Bangladesh J. Bot. 48(4): 1163-1173, 2019 (December)

\title{
ETHNOBOTANIC STUDY OF MEDICINAL PLANTS USED IN ORAN, ALGERIA
}

\author{
Hafsa Benaiche*, Nadia Bouredja and Amel Alioua \\ Laboratoire de Génétique Moléculaire et Cellulaire (LGCM), \\ Département de vivant et de l'environnement, Faculté des Sciences et de la Nature, \\ Université des Sciences et de la Technologie d'Oran Mohamed Boudiaf, Algérie
}

Keywords: Ethnobotanical study, Medicinal plants, Oran, Traditional medicine, Survey

\begin{abstract}
Using 500 survey cards, the ethnobotanical survey was conducted over a period of 4 months. From the survey 62 species belonging to 30 families were identified. The family Lamiaceae is the most dominant followed by Apiaceae. In addition, the leaves are the most used part (38\%). Furthermore, the infusion was the major mode of preparation (66\%). In terms of diseases treated, digestive disorders rank first $(50 \%)$, followed by respiratory diseases $(28 \%)$. The results obtained will be a valuable source of information for the region. There could be a database for further research in the fields of pharmacology and for the purpose of evaluating the therapeutic efficacy of medicinal plants.
\end{abstract}

\section{Introduction}

Since antiquity medicinal plants are used to relieve and cure the human diseases. Their therapeutic properties are due to the presence of hundreds even thousands of natural bioactive compounds called secondary metabolites. Plants have occupied a prominent place and have been used for man a privileged point of contact with nature and health. Popularity of herbal remedies is increasing. They have been tested by our ancestors, of whose virtues confer a significant place in traditional therapy (Tabuti et al. 2003). According to the WHO statistics, about $80 \%$ of African populations use traditional medicine for their primary health care (WHO 2003). In recent years, there has been a remarkable rise of medicinal plant's use, probably due to their local abundance, cultural significance and inexpensive procurement (Thomford et al. 2015). Among the scientific disciplines interested in herbal medicine, ethnobotanics are considered as a field focused on the study of the indigenous and native knowledge on how plants are recognized, used and managed.

Algeria, with its large area and diversified climate has a varied flora, which is a source of rich and abundant medicinal matter. She is one of the richest Arab countries with 3164 plant species (Vasisht and Kumar 2004). On the other hand, Algeria with its history and its strategic location has benefited from different cultures. Important knowledge of plant medicine, currently used in traditional Algerian medicine, originated in the medical heritage of Muslim civilization, transmitted from generation to generation (Chériti et al. 1995). In Oran the second most important city of Algeria the appeal to the herbalist to cure diseases which resist to the conventional medicine became recurring in Oran. Not only because it happens that healing plants are sometimes more efficient than the medicine but also and especially because the cost of medicine is very expensive many inhabitants of Oran do not any more manage to keep up with that. The present work was carried out to explore the medical remedies with an ethnobotanical study of the medicinal plants used by the rural people in Oran, to ascertain the detailed information on plants and their usage and to highlight the role of herbal medicine in the traditional system of care in this city.

*Author for correspondence: <hafsa.benaiche@univ-usto.dz>. 


\section{Materials and Methods}

The city of Oran, Algeria, is a major coastal city located in the north-west of Algeria (Fig. 1), Oran area is at an altitude of $109 \mathrm{~m}$ from the sea level, situated between $35.6971^{\circ} \mathrm{N}, 0.6308^{\circ} \mathrm{W}$. The city of Oran benefits from a classic Mediterranean semi-arid climate marked by a summer drought with soft winters a bright and clear sky. During the summer months the precipitation become rare even non-existent (OSS 2007). The zone of study shelters flora is of ecological and medicinal interest (Trabut 1887).

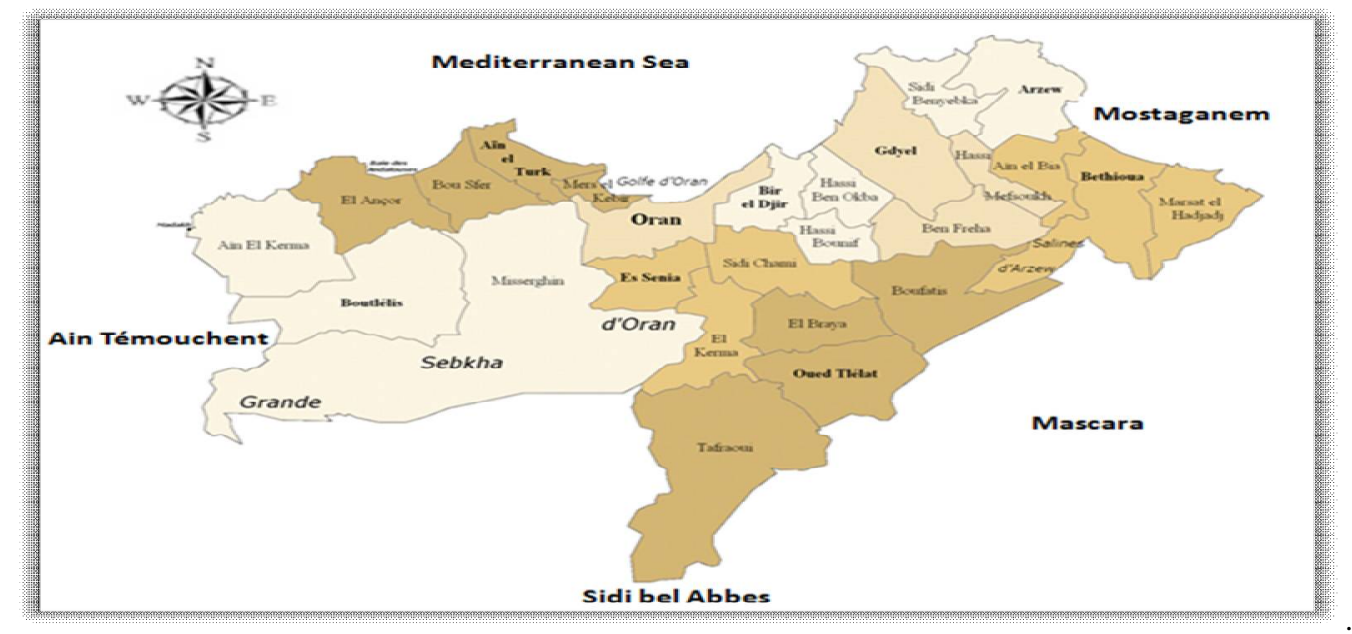

Fig. 1. Study zone.

To improve knowledge on the use of medicinal plants an ethnobotanical survey in the city of Oran was conducted during the period of 4 months (February - May 2018) in collaboration with the inhabitants of the city using a survey (Salhi et al. 2010). All investigations based on the survey allowed as to gather information about research area, details about informants (name, age, gender, educational level), scientific name and local name of plants, part of the plant used, usage purpose of the plant, dosage, how to use it (decoction, infusion, etc.), usage period of the plant. Five hundred people of different ages, gender and intellectual levels from whom information about the most medicinal plants used in the city of Oran were provided.

\section{Results and Discussion}

The general analysis of the survey was made to confirm the significant dependence of the local population towards medicinal plants to treat various diseases. Generally the use of plants in the region of Oran is spread at all the ages, with an ascendancy at people aged from 20 to 40 years old with $67 \%$ followed by the age bracket from 40 to 60 years with a $27 \%$ rate, followed by the age bracket more than 60 years old with $4 \%$, however most low rate was noted at the age bracket less than 20 years old with a $2 \%$ rate (Fig. $2 \mathrm{~A}$ ). It was observed that women used more frequently herbal medicine than men, 81 and 19\%, respectively (Fig. 2B). These observations are in line with results of the studies realized in many regions of Algeria, a neighboring cities whose people share a common culture and traditions have showed that the use of medicinal plant is higher in women than men (Sarri et al. 2014). This could be explained by their attachment to traditional knowledge. Most of the people interrogated were married (57\%) while the singles represent 43\% (Fig. 2D). 
The majority of respondents have an primary, medium and secondary educational level, with a percentage of 10,6 and 22, respectively against 1 illiterate also an important rate was noted at people with university level 61 (Fig. 2C). About the parts of the plants most used for medicinal purposes are in descending (order as shown in graphical representation in (Fig. 4C) leaves (38\%), seeds $(24 \%)$, flowers $(11 \%)$, fruits and rhizome (7\%) aerial parts (leaves and flowers together) $(4 \%)$, whole plant and bark (3\%), roots, bulb and stem (1\%). The use of grains is explained by the

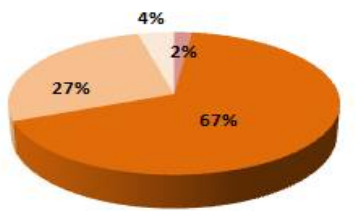

A

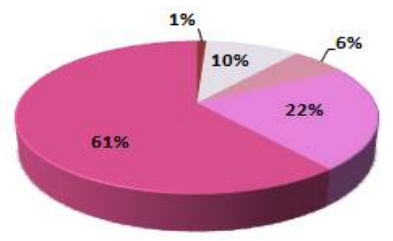

C

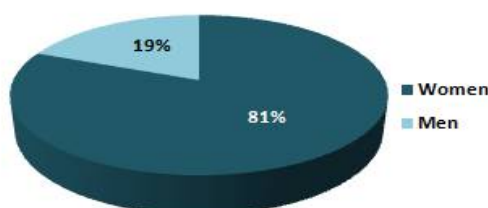

B

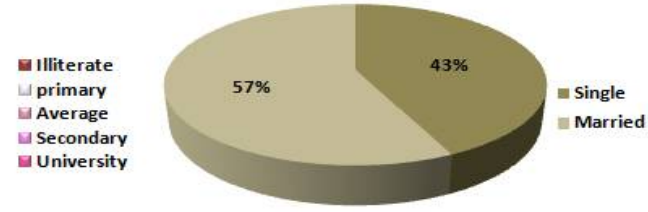

D

Fig. 2. Informants profile results (A: Age, B: Gender, C: Education level, D: Family situation).

ease of their obtaining at the herbalist and their storage also, as for the use of leaves, this raised frequency can be explained by the ease and the speed of the harvest, but also by the fact that they are the seat of the photosynthesis and sometimes the storage of the secondary metabolites responsible for biological properties of the plant (Bigendako-Polygenis and Lejoly 1990), also previous percentage analysis show that leaves were the most frequent part of the plant used just like the report in many other ethonomedicinal studies like (Neves et al. 2009). In the present study, infusion is the most used (66\%), followed of decoction (25\%), cataplasm (3\%), powder and raw (2\%), fumigation and cooked (1\%) (Fig. 4B). It is often reported that the infusion and decoction collect the most active substances and mitigates or cancels the toxic effect of certain ailments (Salhi et al. 2010, Sari et al. 2012). This result shows also that the local population believes in decoction and infusion mode and finds it adequate to warm the body and disinfect the plant (Lahsissène et al. 2009). Among the informants $77 \%$ use spoons of medicinal plant and $22 \%$ use a handle and only $1 \%$ uses a pinch (Fig. 3A). Concerning the treatment duration $42 \%$ of the questioned population use healing plants for a day only and 18\% use them for a week while 3\% use them for a month and 37\% use herbs until the cure (Fig. 3B). About ownership mode of the information about healing plants $43 \%$ of the informants refer to others (family, friends, social networks, TV, internet.), $31 \%$ refer to themselves, $25 \%$ learned it by an herbalist and $1 \%$ by doctors (Fig. 3D). Concerning the treatment efficiency 52\% of the informants think that plants allow a cure, $45 \%$ see that it helps to improve the health on the other hand 3\% think that the plants are ineffective (Fig. 3C). About the posology, adults use plants once a day with a $21 \%$, twice a day with a $67 \%$ and three times a day with a of $4 \%$. As for the elderly $28 \%$ use plants once a day, $51 \%$ use them twice a day and 5\% use herbal plants three times a day and for children $76 \%$ of the people use medicinal herbs once a day while $20 \%$ of the informants use them twice a day while $4 \%$ of people use them three times a day for children. 
From the ethnobotanical survey made in the city of Oran it was possible to identify a number of processed herbs and diseases showing that the population is highly dependent on these plants that allow them to treat various diseases such as digestive diseases (stomach pain) with 50\% followed by respiratory affections (pulmonary disease, bronchitis) with $28 \%$ follow-up of genitourinary affections $13 \%$, cardio-vascular diseases $11 \%$, neurological affections $7 \%$, osteo-articular affections 5\%, metabolic and dermatological diseases 3\% and lastly gland affections with 1\% (Fig. $4 \mathrm{~A})$.

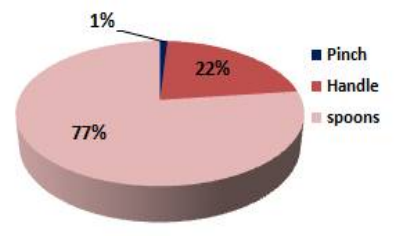

A

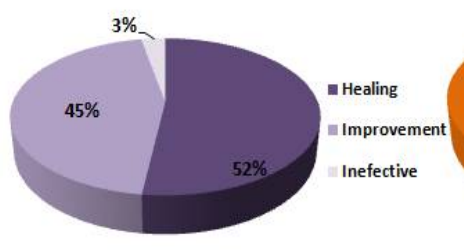

C

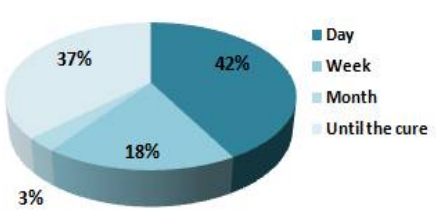

B

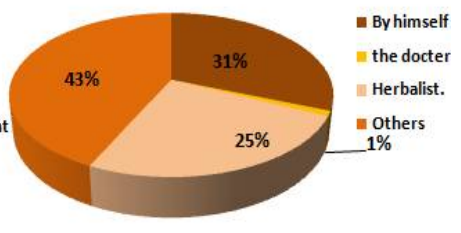

D

Fig. 3. Results of the survey (A. The dose used, B. The using duration, C. Effectiveness, D. Information possession).

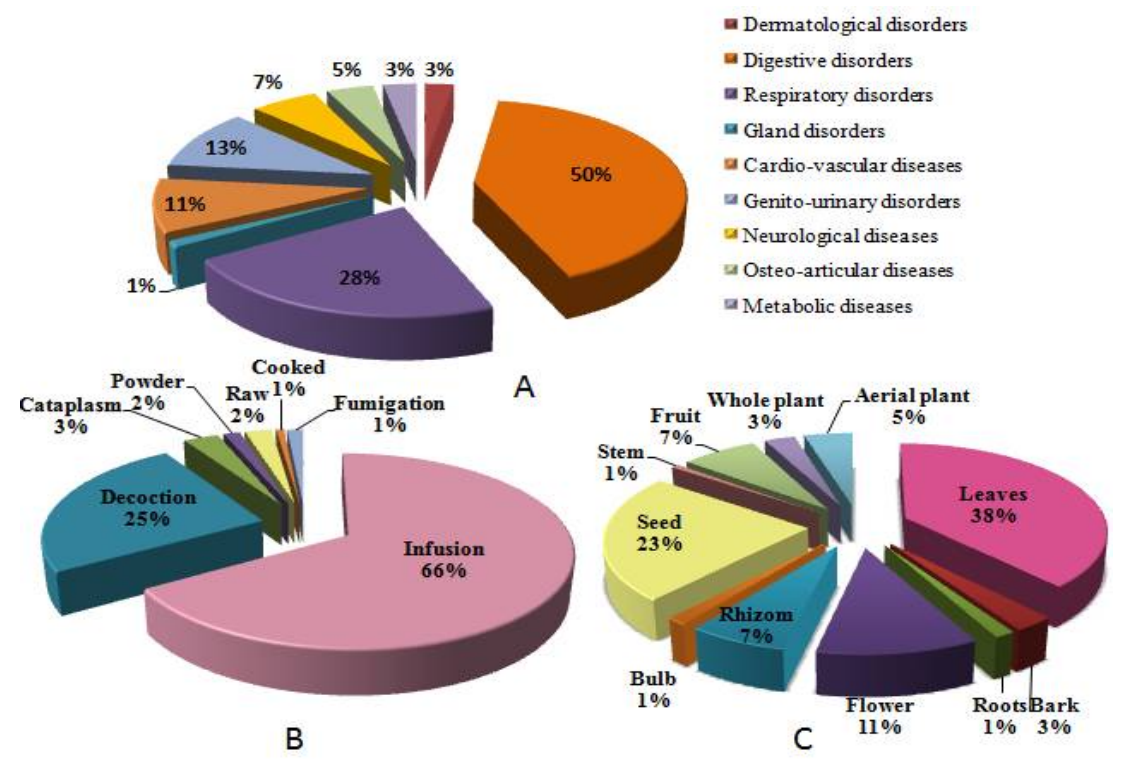

Fig. 4. Ethnobotanical survey results (A. The most diseases treated by medicinal plants cited in the survey, B. Preparation methods used of medicinal plants, C. Most plant parts used). 


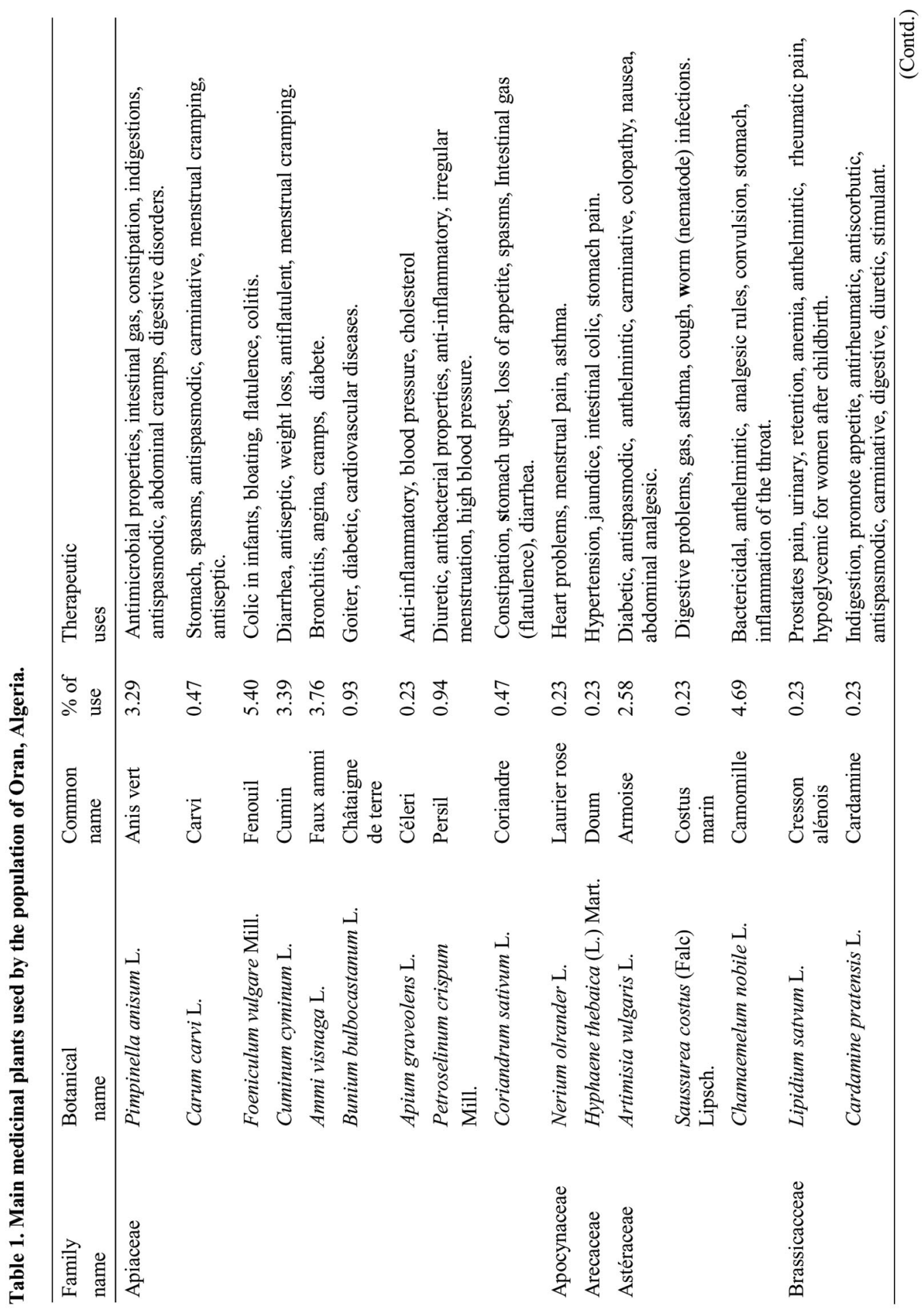




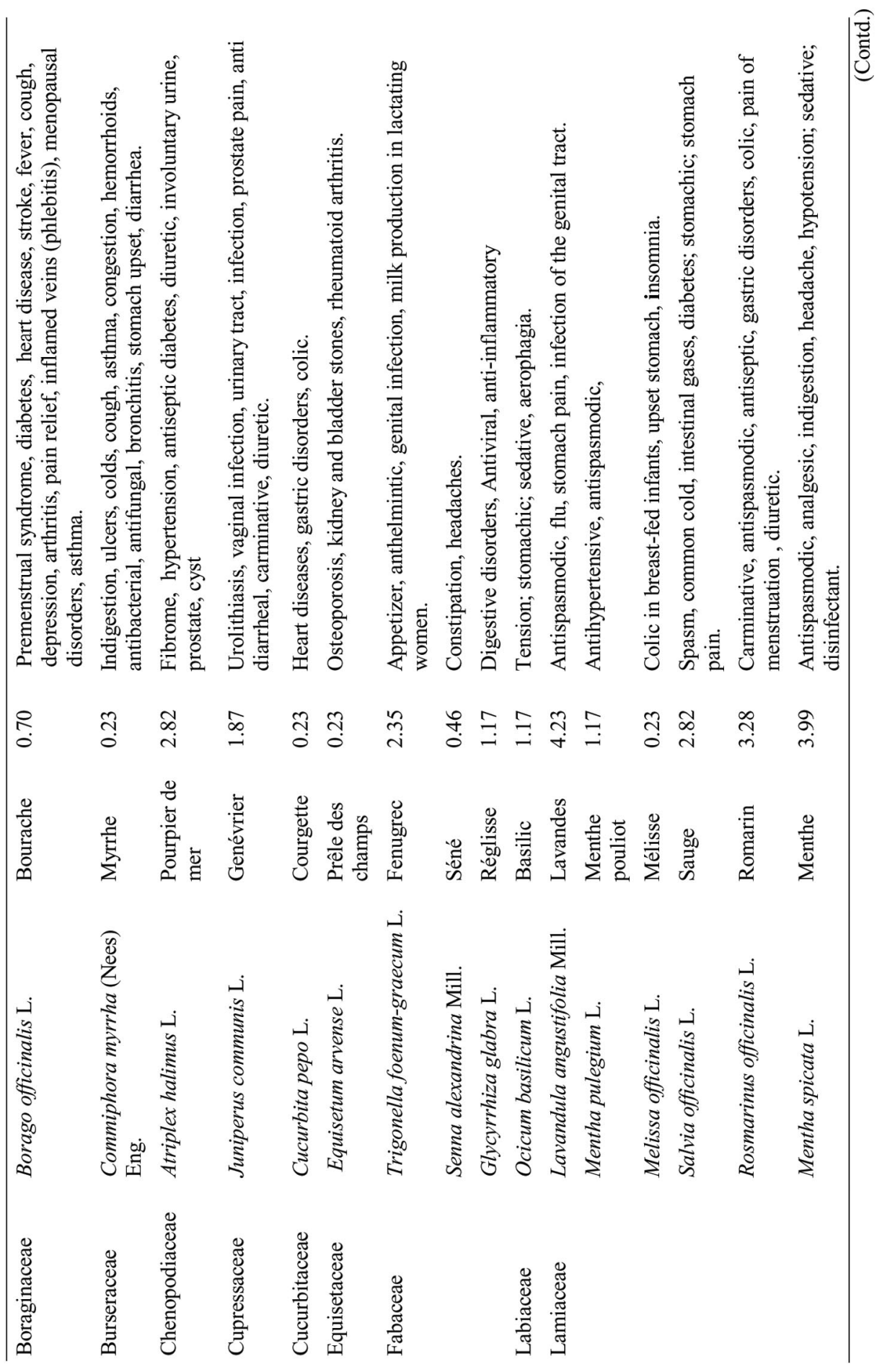




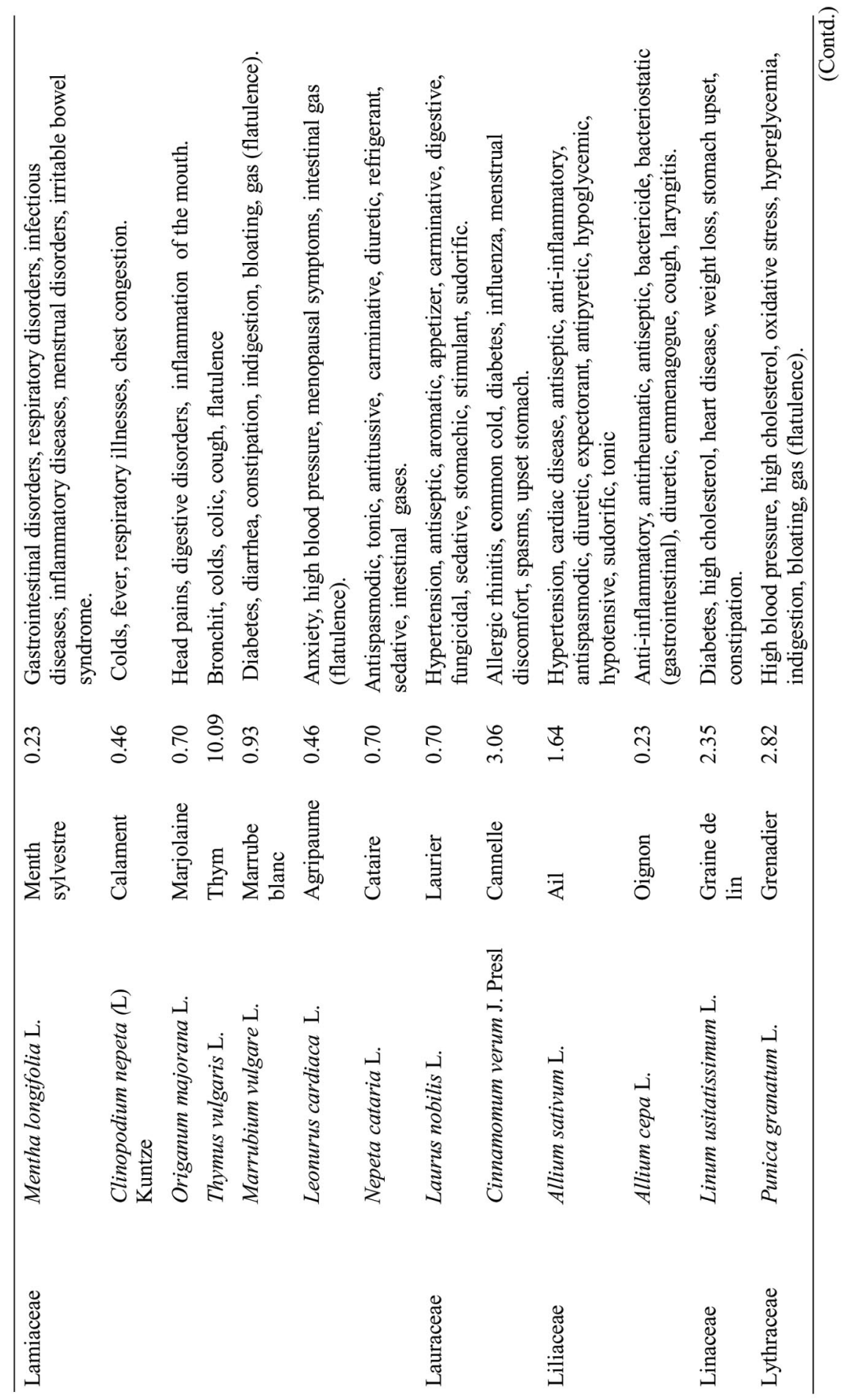




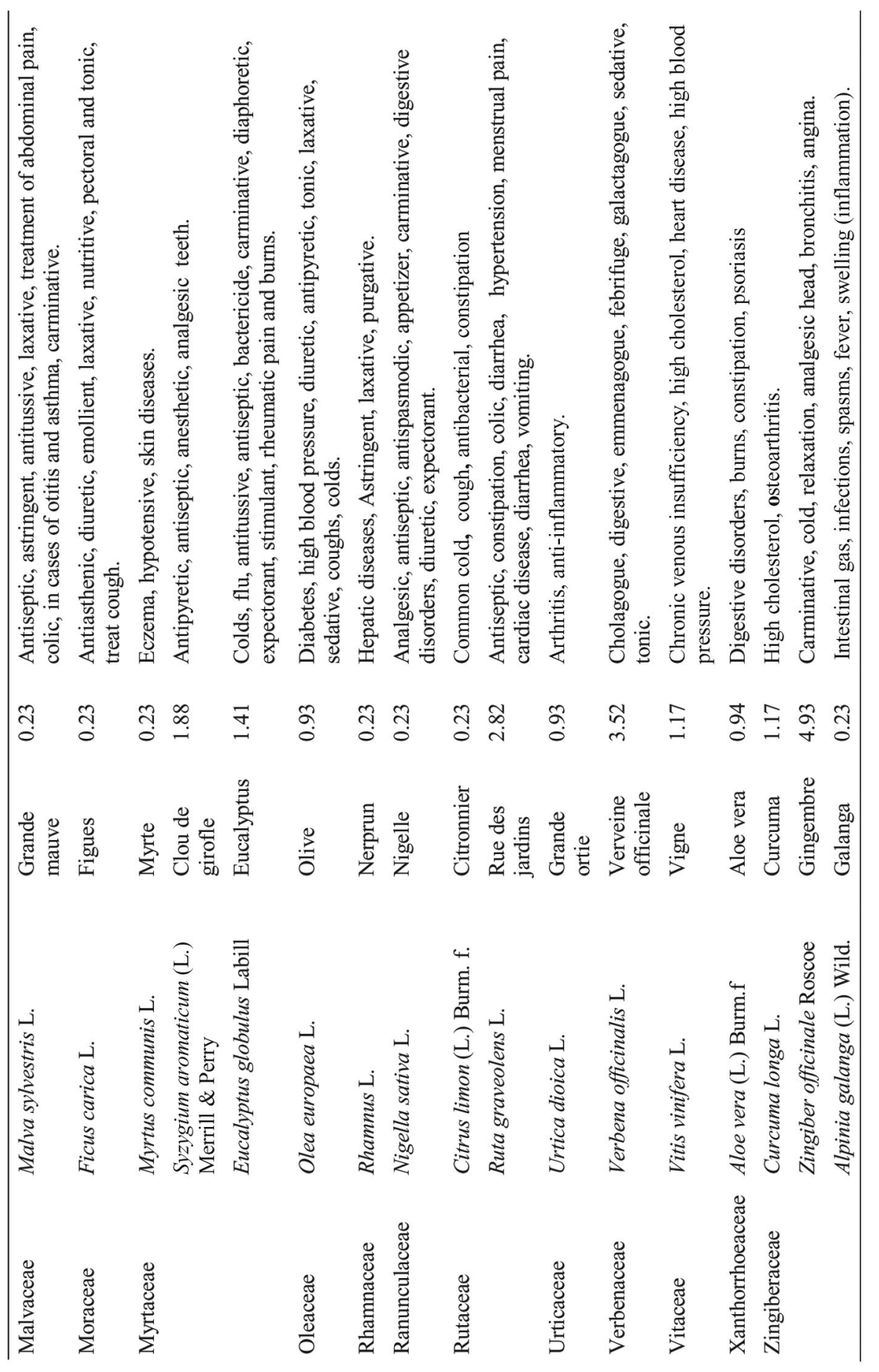


On the basis of 500 questionnaires carried out in the region of Oran, an ethnofloristic catalog was drawn up. The medicinal plants which are usually used by the population of Oran were identified and listed in Table 1. Data were used to carry out floristic study.

Through the survey it was possible to count 62 species of medicinal plants belonging to 30 families. The most represented were: Lamiaceae (13 species), Apiaceae (9 species), Asteraceae (03 species), Fabaceae (3 species), Myrtaceae ( 3 species) and Zingiberaceae (3 species) (Table 1), it can be explained by the fact that these families are the most spread in Algeria and that they are an important part of its flora (Quezel and Santa 1962). This result is in agreement with that obtained by Hseini et al. (2007).

From the ethnobotanical conducted study it is possible to highlight 15 most used medicinal plants by the local population, Thymus vulgaris is the most commonly used (Table 3) due to its effectiveness, people have always used thyme as a culinary herb, and herbal medicine, the plant is useful as infusion to treat cough, diabetes, chest infections and for digestive upset. Thyme has also antiseptic, antibiotic, and antifungal properties (Ekoh et al.2014), followed by Foeniculum vulgare (Table 2) a medicinal and aromatic plant with a diverse pharmacological spectrum, Fennel water has properties similar to those of anise and dill water, these waters are used to treat flatulence of infants. Fennel tea also employed as a carminative (Agarwal et al. 2008), this plant is also used to treat gastritis and irritable colon (Alzweiri et al. 2011). Followed by Zingiber officinalis (Table 3) which has gained interest for its potential to treat various aspects of cardiovascular disease, the anti-inflammatory, antioxidant, antiplatelet and hypotensive effects (Nicoll and Henein 2009). Followed by Chamaemelum nobile that plant has been used for centuries as an anti-inflammatory, antioxidant, chamomile was widely used to treat inflammations

Table 2. Medicinal plants most commonly used in digestive diseases care.

\begin{tabular}{lc}
\hline Plant species & Frequency of use \\
\hline Foeniculum vulgare Mill. & 24 \\
Verbena officinalis L. & 16 \\
Punica granatum L. & 10 \\
Cuminum cyminum L. & 10 \\
Lavandula officinalis Mill. & 10 \\
Artimisia vulgaris L. & 9 \\
Trigonella foenum L. & 9 \\
Pimpinella anisum L. & 9 \\
Juniperus communis L. & 7 \\
Syzygium aromaticum (L.) Merrill \& Perry & 6 \\
\hline
\end{tabular}

of the skin and mucous membranes and for various bacterial infections of the skin, respiratory tract also. It has been frequently used as a mild sedative to calm nerves and reduce anxiety, to treat hysteria, insomnia and other sleep problems (Forster et al. 1980). Followed by other plants as Pimpinella anisum, Cuminum cyminum, Ammi visnaga, Atriplex halimus, Trigonella foenum, Lavandula officinalis, Rosmarinus officinalis, Mentha spicata, Cinnamomum verum, Punica granatum, Verbena officinalis. The most commonly used species in the treatment of digestive and respiratory diseases have been tabulated (Tables 2 and 3). The local residents provided information on the medicinal plant species and the traditional therapeutic practices of the local population of the region of Oran. These medicinal applications spanned a total of 9 disease categories. Each plant might be used to treat various diseases. This can be interpreted as an 
optimization of natural resources due to close connection of the people with their local environment (Pieroni et al. 2002). These plants are a bank of information for those who have decided to take their daily pain differently, neglecting the chemicals in modern medicine. Particularly in the programs of some international organizations such as IUCN that aim, through the involvement of local communities, promote biodiversity conservation and sustainable use of natural resources in the world (Hseini and Kahouadji 2007), although modern medicines may be available in some developing countries, herbal remedies enjoy great popularity for historical and cultural reasons (Aburjai et al. 2007). Concurrently, in many developed countries an increasing number of people have began to turn to alternative medicines or complementary therapies, which include the use of medicinal herbs (Nobili et al. 2009).

Table 3. Medicinal plants most commonly used in respiratory diseases care.

\begin{tabular}{lc}
\hline Plant species & Frequency of use \\
\hline Thymus vulgaris L. & 34 \\
Zingiber officinalis Roscoe & 9 \\
Ammi visnaga L. & 8 \\
Eucalyptus globules Labill & 6 \\
Pimpinella anisum L. & 6 \\
Mentha spicata L. & 5 \\
Marrubium vulgare L. & 4 \\
Juniperus communis L. & 4 \\
\hline
\end{tabular}

The ethnobotanical study made in Oran indicates that the region is very rich in many plants which have a medicinal importance in traditional medicine used by the people. The herbal medicine is very widespread in the Algerian society. The ethnobotanical investigation revealed a multitude of results on the medicinal plants used, this result revealed a big diversity of plants (62 species identified belonging to 30 families). The leaves are the most used part $38 \%$. The preparation mode the most commonly used was infusion, digestive system diseases represent the most cited diseases $(50 \%)$.

Finally, this study presents a useful documentation which can contribute to preserving knowledge on the use of medicinal plants in this region, moreover the results obtained constitute an information base which serves for the valuation of medicinal plants in the field of pharmacology.

\section{Acknowledgement}

The authors thank all the inhabitants of the study area for their cooperation and for providing data on traditional uses of plants.

\section{References}

Aburjai T, Hudaib M, Tayyema R, Yousef M and Qishawi M 2007. Ethnopharmacological survey of medicinal herbs in Jordan, the Ajloun Heights region. J. Ethnopharmacol. 110(2): 294-304.

Agarwal R. Gupta SK. Agarwal SS. Srivastava S and Saxena R 2008. Oculohypotensive effects of Foeniculum vulgare in experimental models of glaucoma. Indian J. Physiol. Pharmacol. 52(1): 77-83.

Alzweiri M, Sarhan AA, Mansi K, Hudaib M and Aburjai T 2011. Ethnopharmacological survey of medicinal herbs in Jordan, the Northern Badia region. J. Ethnopharmacol. 137: 27-35. 
Bigendako-Polygenis MJ and Lejoly, J 1990. La pharmacopée traditionnelle au Burundi. Pesticides et médicaments en santé animale. Ansay N and Thill G (Eds), pp.425-442. Pres. Univ. Namur, Bruxelles Liège.

Chériti A, Rouissat A, Sekkoum K and Balansard G 1995. Plantes de la Pharmacopée traditionnelle dans la région d'El Bayadh, Algérie. Fitoterapia. 66: 525-538.

Ekoh SN, Akubugwo EI, Ude VC and Edwin N 2014. Anti-hyperglycemic and anti-hyperlipidemic effect of spices (Thymus vulgaris, Murraya koenigii, Ocimum gratissimum and Piper guineense) in alloxaninduced diabetic rats. Int. J. Biosci. 4: 179-187.

Forster HB, Niklas H and Lutz S 1980. Antispasmodic effects of some medicinal plants. Planta Med. 40(4): 309-319.

Hseini S and Kahouadji A 2007. Etude ethnobotanique de la flore médicinale dans la région de Rabat. Maroc occidental. Lazaroa. 28 :79-93.

Lahsissène H, Kahouadji A, Tijane M and Hseini S 2009. Catalogue des plantes médicinales utilisées dans la région de Zaër. Maroc Occidental. Lejeunia, Revue de Botanique. 186: 1-27.

Neves JM, Carla MC, Moutinho C, Queiroz G and Gomes LR 2009. Ethnopharmacological notes about ancient uses of medicinal plants in Tras-os-Montes, northern of Portugal. J. Ethnopharmacol. 124: 270283.

Nicoll R and Henein M Y 2009. Ginger (Zingiber officinale Roscoe): A hot remedy for cardiovascular disease. Int. J. Cardiol. 131(3): 408-9.

Nobili S, Lippi D, Witort E, Donnini M, Bausi L, Mini E and Capaccioli S 2009. Natural compounds for cancer treatment and prevention. Pharmacol Res. 59(6): 365-378.

OSS (Observatoire du Sahara et du Sahel) 2007. Cartographie institutionnelle de l'adaptation en Afrique du Nord. Convention OSS/ ACCA-CRDI.

Pieroni A, Nebel S, Quave C, Münz H and Heinrich M 2002. Ethnopharmacology of liakra: Traditional weedy vegetables of the Arbëreshë of the Vulture area in southern Italy. J. Ethnopharmacol. 81(2): 16585.

Quezel P and Santa S 1963. Nouvelle flore de l'Algérie et des régions désertiques méridionales. Editions CNRS.Paris, 1170.

Salhi S, Fadli M, Zidane L and Douira A 2010. Floristic and ethnobotanical study of medicinal plants of Kénitra (Maroc).Lazaroa. 31: 133-146.

Sari M, Hendel N, Boudjelal A and Sarri Dj 2012.Inventory of medicinal plants used for traditional treatment of Eczema in the region of Hodna. M'sila Algeria. Global J. Res. Med. Plants Indig. Med. 1(4): 97-100.

Sarri M, Mouyet FZ, Benziane M and Cheriet A 2014.Traditional use of medicinal plants in a city at steppic character M'sila, Algeria. J. Pharm. Pharmacogn. Res. 2(2): 31-35.

Tabuti JR, Lye KA and Dhillion SS 2003. Traditional herbal drugs of Bulamogi.Uganda: Plants, use and administration. J. Ethnopharmacol. 88(1): 19-44.

Thomford NE, Dzobo K, Chopera D, Wonkam A, Skelton M and Blackhurst D 2015. Pharmacogenomics implications of using herbal medicinal plants on African populations in health transition. Pharmaceuticals 8: 637-63.

Trabut L (Eds) 1887. D’Oran à Mecheria : notes botaniques et catalogues des plantes remarquables. Alger, Adolphe Jourdan. p. 36.

Vasisht K and Kumar V 2004. Compendium of Medicinal and Aromatic Plants. Africa: ICS-UNIDO 1: 2356.

WHO 2003b. Traditional Medicine. Fifty-Sixth World Health Assembly, Provisional agenda item 14.10.31 March 2003. World Health Organization Press, Geneva. 